REVIEW SERIES

\title{
Cough - 5: The type 1 vanilloid receptor: a sensory receptor for cough
}

\section{A H Morice, P Geppetti}

Thorax 2004;59:257-258. doi: 10.1136/thx.2003.013482

Evidence is presented to support the proposal that activation of the type 1 vanilloid receptor (VR1) is an important sensory mechanism in cough. antagonist capsazepine has been found to inhibit both citric acid and capsaicin induced cough in animals. ${ }^{7}$ Thus, both capsaicin and protons appear to be acting through a common pathway, albeit at different allosteric sites. Recent advances in the understanding of the molecular activity of VRl have indicated how these observations can be unified to produce a coherent description of a putative cough receptor. tom. According to the 1992 morbidity statistics in general practice, acute "viral" cough accounts for the largest single cause of new consultations with GPs with an annual expenditure in 1999 of more than $£ 200$ million in the UK, mostly on medicines which are, at best, poorly effective. Chronic cough arises from a number of different pathologies and is a common and problematic source of referral to chest physicians. However, despite half a century of research, the pathophysiological mechanisms causing cough are poorly understood. In particular, the receptor that stimulates the afferent arm of the cough reflex has not been characterised in detail.

\section{CAPSAICIN-LIKE DRUGS CAUSING COUGH}

In man, inhalational cough challenge has been used since $1954^{1}$ to study the profile of agonists and inhibitors of the reflex. These peripherally acting stimulants-which presumably act on or in close association with the putative sensory receptor-can be divided into two broad groups: (1) organic and inorganic acids and (2) agonists of the type 1 vanilloid receptor (VRI) such as capsaicin and resinoferatoxin. These latter agents are the most potent stimulants of the cough reflex so far described in man. ${ }^{23}$ Type 1 vanilloid receptors have been intensively studied in their role as the mediators of pain in skin and other tissues. ${ }^{45}$ When these receptors are exposed to noxious stimuli they act as ion channels with increased permeability to $\mathrm{Na}^{+}$and $\mathrm{Ca}^{2+}$ ions. This influx of ions causes neuronal depolarisation and caudal propagation of action potentials. It is our belief that VRl activation is the primary sensory mechanism in cough, and recent evidence has suggested how factors known to promote cough may act through this common pathway.

We have previously studied the mechanism of acid induced cough in man. In subjects undergoing cough challenge there is a significant correlation between different acids associated with their ability to donate protons. In contrast, there is no correlation with capsaicin responses. ${ }^{6}$ This finding could be taken as evidence for two separate mechanisms, but the capsaicin
THE TYPE 1 VANILLOID RECEPTOR (VR 1 )

VRI has been cloned ${ }^{4}$ and is structurally related to the transient receptor potential family of ion channels. Rat VRI consists of 432 amino acids and is predicted to have six transmembrane spanning domains. When expressed in cell lines not containing constitutive vanilloid receptors, patch clamping studies have confirmed that it acts as a non-specific ion channel with similar electrophysiological properties to the native receptor. ${ }^{48}$ In particular, the opening probability of VRl increases not only with exogenous capsaicin but also in response to noxious stimuli such as protons and heat. The site of proton binding was identified by site directed mutagenesis on the extracellular aspect of the fifth transmembrane domain near the putative pore forming region. ${ }^{9}$

VRl has been shown to be sensitive to a fall in the extracellular $\mathrm{pH}$, and $\mathrm{H}^{+}$ions not only stimulate the receptor directly $y^{8}$ but also increase the sensitivity of the receptor to capsaicin. ${ }^{4}$ Since cough may be stimulated by the direct application of acid to the airway, this implies that, if VRl is important in cough, an endogenous capsaicin-like ligand must also be present. A number of putative ligands have been suggested, usually lipids because of the hydrophobic nature of capsaicin. Anandamide, the endogenous agonist of the cannabinoid receptor, does appear to have some activity on VRl in vitro but, when inhaled by a single capsaicin sensitive subject, did not have any demonstrable activity apart from an unpleasant taste. That anandamide is unlikely to be the endogenous full agonist of VRI has been confirmed in other systems and, indeed, may even inhibit cough. ${ }^{10}$

An important advance in our understanding of the biology of VRl was the demonstration that the capsaicin binding site was located on the cytosolic domain of the receptor. ${ }^{11}$ Thus capsaicin, unlike most other ligands, traverses the cell membrane and stimulates VRl intracellularly (fig 1). It was logical therefore for the search for the endogenous capsaicin-like ligand to be directed within the neurone. It has now been 


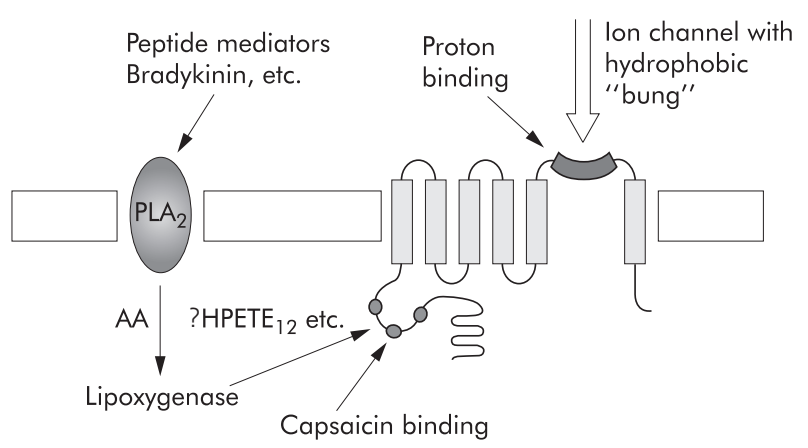

Figure 1 The putative type 1 vanilloid cough receptor (VR1) illustrating possible regulation by inflammatory mediators capsaicin and protons. $\mathrm{AA}=$ arachidonic acid; HPETE = hydroperoxyeicosatetraenoic acid; $\mathrm{PLA}_{2}=$ phospholipase $\mathrm{A}_{2}$.

shown that lipoxygenase products are potent agonists at the capsaicin binding site. ${ }^{12}$

\section{ENDOGENOUS LIGANDS OF VR 1}

The lipoxygenase enzymes catalyse the conjugation of a hydroperoxide moiety with arachidonic acid to produce one of a family of hydroperoxyeicosatetraenoic acids (HPETE). In asthma, 5-lipoxygenase produces 5-HPETE which is the precursor of the leukotrienes. However, there are a number of other lipoxygenase products named after the position of conjugation with arachidonic acid. In animal species from molluscs to mammals, HPETEs have been shown to regulate neurotransmission by increasing the opening probability of ion channels such as $\mathrm{K}^{+}$channels. ${ }^{13-15}$ Patch clamping studies have shown that 12-HPETE is endowed with many of the characteristics that would be predicted for an endogenous capsaicin-like ligand. 12-HPETE strongly activates single channel currents with an identical current voltage relationship to capsaicin. As with capsaicin, $\mathrm{Na}^{+}$and $\mathrm{K}^{+}$ions are conducted and capsazepine blocks the opening of the channel. These studies were performed in primary culture of dorsal root ganglia of the rat and, while 12-HPETE was the most potent putative ligand, other lipoxygenase products including $\mathrm{LTB}_{4}$ were also active. More recently we have shown that another lipid derivative, $N$-arachidonoyl-dopamine (NADA), activates VRl in different animal models and also at the recombinant human VRl more potently than anandamide and lipoxygenase derived molecules. ${ }^{16}$ However, it is not known whether NADA is the most potent endogenous ligand of human VRl.

Inflammatory stimuli-including prostaglandins, bradykinin, nerve growth factor, and others-have been shown to upregulate the expression and function of VRl via the activation of p38MAPK, PLC- $\gamma$, PKC- $\epsilon$, and PKA dependent pathways. ${ }^{17-19}$ Chronic airway inflammation such as that present in asthma, COPD, and other lung diseases may therefore exaggerate the sensitivity of VRI to its agonists which, in these conditions, may reach a concentration sufficient to trigger the VRl dependent cough reflex.

\section{CONCLUSIONS}

There is a convincing case for the promotion of VRl as the lead candidate to be the first cloned and characterised cough receptor. The final proof must await the development of a potent and specific antagonist for use in man. It is unlikely that VRl activation is the only stimulus for cough since some tussogenic agents such as distilled water are not inhibited by VRl antagonism. ${ }^{7}$ That VRl is a member of a growing family of structurally similar ion channels suggests a heterogeneous system which will require further dissection if we are to understand the biochemical basis of cough in health and disease.

\section{Authors' affiliations}

A H Morice, Department of Respiratory Medicine, University of Hull, Castle Hill Hospital, Cottingham, East Yorkshire HU16 5JQ, UK P Geppetti, Department of Critical Care Medicine and Surgery, Medical School, University of Florence, 50139 Florence, Italy

\section{REFERENCES}

1 Bickerman HA, Barach AL, Itkin S, et al. Experimental production of cough in human subjects induced by citric acid aerosols. Preliminary studies on the evaluation of antitussive agents. Am J Med Sci 1954;228:156-63.

2 Laude EA, Higgins KS, Morice AH. A comparative study of the effects of citric acid, capsaicin and resiniferatoxin on the cough challenge in guinea-pig and man. Pulm Pharmacol 1993:6:171-5.

3 Collier JG, Fuller RW. Capsaicin inhalation in man and the effects of sodium cromoglycate. Br J Pharmacol 1984;81:113-7.

4 Caterina MJ, Schumacher MA, Tominaga $M$, et al. The capsaicin receptor: a heat-activated ion channel in the pain pathway. Nature 1997;389:816-24.

5 Szallasi A. The vanilloid (capsaicin) receptor: receptor types and species differences. Gen Pharmacol 1994;25:223-43.

6 Wong CH, Matai R, Morice AH. Cough induced by low pH. Respir Med 1999;93:58-61.

7 Lalloo UG, Fox AJ, Belvisi MG, et al. Capsazepine inhibits cough induced by capsaicin and citric acid but not by hypertonic saline in guinea pigs. J Appl Physiol 1995;79:1082-7.

8 Tominaga M, Caterina MJ, Malmberg AB, et al. The cloned capsaicin receptor integrates multiple pain-producing stimuli. Neuron 1998;21:531-43.

9 Jordt SE, Tominaga M, Julius D. Acid potentiation of the capsaicin receptor determined by a key extracellular site. Proc Natl Acad Sci USA 2000;97:8134-9.

10 Calignano A, Katona I, Desarnaud F, et al. Bidirectional control of airway responsiveness by endogenous cannabinoids. Nature 2000;408:96-101.

11 Jung J, Hwang SW, Kwak J, et al. Capsaicin binds to the intracellular domain of the capsaicin-activated ion channel. J Neurosci 1999;19:529-38.

12 Hwang SW, Cho H, Kwak J, et al. Direct activation of capsaicin receptors by products of lipoxygenases: endogenous capsaicin-like substances. Proc Natl Acad Sci USA 2000;97:6155-60.

13 Piomelli D, Volterra A, Dale N, et al. Lipoxygenase metabolites of arachidonic-acid as second messengers for presynaptic inhibition of aplysia sensory cells. Nature 1987;328:38-43.

14 Piomelli D, Greengard P. Lipoxygenase metabolites of arachidonic-acid in neuronal transmembrane signaling. Trends Pharm Sci 1990;11:367-73.

15 Schweitzer P, Madamba S, Siggins G. Arachidonic-acid metabolites as mediators of somatostatin-induced increase of neuronal m-current. Nature 1990;346:464-7.

16 Huang SM, Bisogno T, Trevisani M, et al. An endogenous capsaicin-like substance with high potency at recombinant and native vanilloid VR 1 receptors. Proc Natl Acad Sci USA 2002;99:8400-5.

17 Chuang $\mathbf{H H}$, Prescott ED, Kong $\mathrm{H}$, et al. Bradykinin and nerve growth factor release the capsaicin receptor from Ptdlns(4,5)P2-mediated inhibition. Nature 2001;411:957-62.

18 De Petrocellis L, Harrison S, Bisogno T, et al. The vanilloid receptor (VR1)mediated effects of anandamide are potently enhanced by the CAMPdependent protein kinase. J Neurochem 2001;77:1660-3.

19 Ji R, Samad T, Jin S, et al. p38 MAPK activation by NGF in primary sensory neurons after inflammation increases TRPV1 levels and maintains heat hyperalgesia. Neuron 2002;36:57-68. 